\title{
IBAS: uma análise das ações quinze anos depois
}

\section{IBSA: an analysis of the actions fifteen years later}

Marcelo Xavier

Universidade Federal de Pernambuco (UFPE)

E-mail: marceloxn@hotmail.com

Pedro Fonseca

Universidade Federal de Pernambuco (UFPE)

E-mail: pe.fonseca@outlook.com

Resumo: O IBAS é um relevante instrumento de cooperação sul-sul que nasceu como uma plataforma de debates para uma instituição com objetivos bem delineados. Passados 15 anos desde sua criação, quais foram os avanços mais salientes deste arranjo institucional? A partir disso, este texto fez um balanço dos resultados, a partir do confronto entre os resultados concretos do Fórum e as declarações oficiais. Foi constatado que o Fundo IBAS além de ser a face mais visível do Fórum IBAS é o principal instrumento para os objetivos comuns dos países-membros. A partir da conceituação da cooperação sul-sul será feito uma comparação dos objetivos iniciais do fórum com seus resultados após quinze anos.

Palavras-Chave: Cooperação Sul-Sul; IBAS; Cooperação.

\begin{abstract}
The IBSA is a relevant South-South cooperation instrument that was born as a platform for debates for an institution with well-defined objectives. After 15 years since its creation, what were the most salient advances of this institutional arrangement? From this, this text took stock of the results, from the confrontation between the concrete results of the Forum and the official declarations. It has been found that the IBSA Fund as well as being the most visible face of the IBSA Forum is the main instrument for the common objectives of the member countries. From the conceptualization of South-South cooperation, a comparison of the initial objectives of the forum with its results will be made after fifteen years.
\end{abstract}

Keywords: South-South Cooperation; IBSA; Cooperation. 
XAVIER, Marcelo; FONSECA, Pedro. IBAS: uma análise das ações quinze anos depois.

\section{Introdução}

O IBAS nasceu da insatisfação dos países-membros com o funcionamento das instâncias de globais de poder e com o objetivo de claro de trabalhar por mudanças nas instituições multilaterais. O relevo dessa pauta é explícito na Primeira Declaração Conjunta de Presidentes (2006), que dedicou 2/3 do conteúdo às questões a temas internacionais 1 Contudo, o escopo do Fórum é bem mais amplo e contempla interesses em cooperação trilateral em esferas técnicas e políticas mirando impulsionar o desenvolvimento conjuntos dos membros.

Chama atenção que o IBAS é um dos primeiros organismos de cooperação sul-sul a se destacar nesse século. É patente que o momento atual apresenta uma nova correlação de forças, onde as potências emergentes ganham força na balança de poder global e ampliam seus poderes de barganha quando se unem em torno de pautas comuns. Por isso é relevante discutir os avanços do IBAS como um bloco coeso de poderes emergentes e como suas iniciativas concorrem para atingir os objetivos até então. Sendo assim, a pergunta de pesquisa que o trabalho busca responder é: "Quais foram os resultados do IBAS após quinze anos de existência?" A hipótese que orienta o artigo é que apesar de contemplar muitos temas, o Fórum avançou principalmente no tema de combate e alívio à pobreza através do Fundo IBAS. Em consequência do sucesso do fundo, o coro por mudanças na governança global ganhou musculatura.

$\mathrm{O}$ artigo se divide em quatro seções e os dados apresentados no corpo do trabalho foram coletados no Overview of the IBSA Fund Project Portfolio 2018 do IBSA Fund, nos Ministérios as Relações Exteriores dos países-membros e instituições de pesquisa diversas.

\section{A Cooperação Sul-Sul: Histórico, desenvolvimento e políticas}

O desenvolvimento das nações periféricas esbarra em obstáculos cuja resolução passa pela construção de coalizões com objetivos comuns. A estrutura de governança global não atende aos interesses dos países em ascensão e ao mesmo tempo faltam-lhes recursos e competências internas para impulsionar o desenvolvimento.

\footnotetext{
1 Dos 65 pontos da Declaração Conjunta, 42 trataram de temas relacionados à governança e segurança internacional.
}

Revista Brasileira de Políticas Públicas e Internacionais, v.4, n.1, julho/2019, pp. 175-194. 
XAVIER, Marcelo; FONSECA, Pedro. IBAS: uma análise das ações quinze anos depois.

A partir dessa premissa será apresentado o desenvolvimento da Cooperação Sul-Sul (CSS) ao longo do século XX. Antes disso é importante pontuar a dificuldade em torno do desenvolvendo de uma definição sobre CSS. A imprecisão em conceituar a Cooperação Sul-Sul surge inicialmente a partir a dificuldade de enquadrar quais relações entre países do Sul podem ser definidas como CSS. Uma visão inspirada no pensamento dos teóricos da dependência, definiria a Cooperação Sul-Sul como um mecanismo utilizado países do sul global para superar a condição de dependência que possuem com os países do norte a partir do fortalecimento da cooperação técnica, política e econômica (De La Fontaine \& Seifert, 2010).

Num prisma mais formal, a Agência Brasileira de Cooperação (ABC) fala da cooperação em sentido técnico como um:

[...] importante instrumento de desenvolvimento, auxiliando um país a promover mudanças estruturais nos campos social e econômico, incluindo a atuação do Estado, por meio de ações de fortalecimento institucional. Os programas implementados sob sua égide permitem transferir ou compartilhar conhecimentos, experiências e boas-práticas por intermédio do desenvolvimento de capacidades humanas e institucionais, com vistas a alcançar um salto qualitativo de caráter duradouro (ABC, 2012, s.p.)

No entanto, Milani e Carvalho (2013) apontam que a definição da ABC por ser restrita ${ }^{2}$, deixa de abarcar uma série de dimensões que também podem ser caracterizadas como Cooperação Sul-Sul. São excluídas dessa definição questões políticas e objetivos para além do escopo das áreas técnicas apontadas. Desse modo, o presente artigo utilizará a definição dos autores que define a CSS como sendo:

[...] uma gama ampla de formas de cooperação entre países em desenvolvimento, desde os espaços multilaterais de negociação (por exemplo, o G-77 ou o G-20 comercial), a formação de coalizões políticas (IBAS, BRICS, por exemplo), passando pela promoção do comércio Sul-Sul (ALADI, SADC), pela construção de espaços regionais de integração (MERCOSUL, UNASUL), financiamento de projetos de infraestrutura via empréstimos subsidiados, até modalidades de transferência de tecnologia, intercâmbio de experiências no campo das políticas públicas e cooperação técnica por meio de ministérios, agências, entidades subnacionais, universidades e organizações não governamentais (MILANI \& CARVALHO, 2013, p.16).

2 A ABC utiliza o termo "cooperação técnica entre países em desenvolvimento" (CTPD).

Revista Brasileira de Políticas Públicas e Internacionais, v.4, n.1, julho/2019, pp. 175-194. 
XAVIER, Marcelo; FONSECA, Pedro. IBAS: uma análise das ações quinze anos depois.

A Conferência de Bandung é considerada um marco para a Cooperação Sul-Sul (CSS), pois é nessa reunião que surgem "os primeiros passos da cooperação política entre países em desenvolvimento com o objetivo de combater as diferentes versões do colonialismo e da dominação ocidental, em nome da solidariedade entre os países do Terceiro Mundo" (Milani \& Carvalho, 2013, p.13). É em Bandung que se enxerga a necessidade de um maior aprofundamento nas relações entre os países asiáticos e africanos, criando uma alternativa para o que se tinha na conjuntura presente, ou seja, duas superpotências, Estados Unidos da América (EUA) e União das Repúblicas Socialistas Soviéticas (URSS), disputando a hegemonia, buscando atrair os demais países para o seu centro de gravidade. É a partir dessa conjuntura, surge em Bandung, apesar da sua fundação só ocorrer em Belgrado em 1961, o Movimento dos Não Alinhados (MNA).

Em 1964, ocorre a Primeira Conferência das Nações Unidas sobre Comércio e Desenvolvimento (UNCTAD) que surge por uma demanda de parte dos países em desenvolvimento com o argumento que o GATT (General Agreement on Tariffs and Trade) ou Acordo Geral sobre Tarifas e Comércio não atendia os produtos exportados por esses países. Em 1978, no âmbito da UNCTAD, ocorre na Argentina uma conferência envolvendo 138 países, reforçando a Cooperação Sul-Sul. Nessa reunião, como pontua Renzio et al (2013) surge o Plano de Ação de Buenos Aires (PABA), que buscava promover a cooperação técnica entre países em desenvolvimento e no qual o termo "cooperação horizontal" aparece pela primeira vez.

No entanto, nas duas últimas décadas do século XX a CSS passou por um período conturbado devido ao contexto global, perdendo, desse modo, relevância. Tal fato ocorre devido à crise que os países em desenvolvimento se encontravam devido ao endividamento externo, além disso, como pontua Milani e Carvalho (2013), com a crise sistêmica dos modelos nacional-desenvolvimentistas e a aceleração dos processos de globalização, observa-se o aprofundamento da dependência da cooperação Norte-Sul. Apesar dessa perda de relevância, é no século XX que há o surgimento de múltiplas ações de CSS que buscam promover amplas formas de cooperação entre os países do sul global nas mais variadas áreas, como se pode observar no Quadro 1 que apresenta as principais iniciativas ao logo do tempo.

Revista Brasileira de Políticas Públicas e Internacionais, v.4, n.1, julho/2019, pp. 175-194. 
XAVIER, Marcelo; FONSECA, Pedro. IBAS: uma análise das ações quinze anos depois.

Quadro 1: Principais iniciativas de Cooperação Sul-Sul por ano.

\begin{tabular}{|c|c|}
\hline Iniciativas & Ano \\
\hline Conferência de Bandung & 1955 \\
\hline $\begin{array}{c}\text { Organização do Países Exportadores de } \\
\text { Petróleo }\end{array}$ & 1960 \\
\hline Movimento dos Não Alinhados (MNA) & 1961 \\
\hline $\begin{array}{c}\text { I Conferência das Nações Unidas sobre } \\
\text { Comércio e Desenvolvimento }\end{array}$ & 1964 \\
\hline G-77 & 1964 \\
\hline Conferência de Buenos Aires & 1978 \\
\hline Programa de Arusha & 1979 \\
\hline Programa de Ação de Caracas & 1981 \\
\hline Agência Brasileira de Cooperação (ABC) & 1987 \\
\hline Unidade de Cooperação Sul-Sul (PNUD) & 1996 \\
\hline Primeiro Fórum de Cooperação China-África & 2000 \\
\hline Fórum Índia-Brasil-África do Sul (IBAS) & 2003 \\
\hline Primeira Cúpula do Sul & 2003 \\
\hline Conferência de Alto-Nível das Nações Unidas & 2009 \\
\hline sobre Cooperação Sul-Sul & 2009 \\
\hline I Cúpula dos BRICS & 2015 \\
\hline Primeiro Fórum China-CELAC & \\
\hline
\end{tabular}

Fonte: Elaboração própria a partir dos dados de Milani e Carvalho (2013)

Além disso, ainda observando o Quadro 1, nota-se que o século XXI traz uma nova pujança de cooperações, com destaque para o BRICS, fórum criado pelas grandes potências emergentes Brasil, Rússia, Índia, China e África do Sul; o Fórum CHINA-CELAC que congrega a República Popular da China com a Comunidade de Estados Latino-Americanos e Caribenhos e o Fórum de Diálogo Índia, Brasil e África do Sul (IBAS).

Cabe ressaltar um ponto importante levantado por Milani e Carvalho (2013, p.15) que diz respeito aos pressupostos formulados nesse começo de século XXI, ou seja, "de que os países em desenvolvimento podem e devem cooperar entre si com a finalidade de garantir reformas políticas da governança global (FMI, Banco Mundial, ONU) e resolver problemas econômicos e sociais com base em identidades compartilhadas (ex-colônias, status econômico, experiência histórica, etc.), esforços comuns, interdependência e reciprocidade”.

Por fim, é necessário notar que a Cooperação Sul-Sul, assim como a Cooperação NorteSul, não pode ser considerada como algo homogêneo, tendo em vista que os países em desenvolvimento, mesmo possuindo similaridades, estão em graus de desenvolvimento

Revista Brasileira de Políticas Públicas e Internacionais, v.4, n.1, julho/2019, pp. 175-194. 
XAVIER, Marcelo; FONSECA, Pedro. IBAS: uma análise das ações quinze anos depois.

diferentes, além de possuírem características idiossincráticas de cada sociedade (Narlikar, 2010; Milani \& Carvalho, 2013).

\section{IBAS: A nova geografia política.}

O IBAS é criado em 6 de junho de 2003 a partir da Declaração de Brasília com o objetivo declarado de "examinar temas da agenda internacional e de interesse mútuo" (IBAS, 2003, p.01). Fruto de uma proposta da África do Sul, que argumentava que o G-8, grupo dos sete países mais industrializados mundo ${ }^{3}$ mais a Rússia ${ }^{4}$, não correspondia mais como único formulador de soluções para o mundo, sendo necessária a visão dos países em desenvolvimento.

Faz-se necessário pontuar que a formulação de um "G-8 do Sul”, como afirma Almeida Filho (2013, p.20), encontrou entraves. O principal refere-se ao fato de que o grupo poderia reunir países que apesar de estarem inseridos no mundo em desenvolvimento não compartilhariam posições e ideias dos demais, como por exemplo, o ideal democrático. Exemplo disso é o fato da sondagem de países como China e Arábia Saudita (Almeida Filho, 2013; Amorim, 2013). Desse modo, o IBAS foi formado por um G-3, resguardando as características que singularizam os membros.

Em seu livro intitulado "Breves Narrativas diplomáticas", Celso Amorim destina um capítulo sobre o Fórum de Diálogos Brasil, África do Sul e Índia. No capítulo "IBAS: a nova geografia política" o ex-ministro do Ministério das Relações Exteriores (MRE) do governo Lula (2003-2011) relata como se deu o surgimento e demonstra a relevância desse importante fórum de diálogo entre os países. Apesar das distâncias geográficas, o Fórum de Diálogo Índia, Brasil e África do Sul (IBAS) reúne três países que apesar das distâncias geográficas, compartilham muitas semelhanças, dentre as quais são grandes democracias multiétnicas.

Segundo a Declaração de Brasília, os fatores que justificam a aproximação da Índia, Brasil e África do Sul é o fato dos países constituírem-se como nações democráticas, inseridas no mundo em desenvolvimento e atuantes em escala global. Outros fatores que não constam na Declaração, mas são observados por Almeida Filho (2009), e que reforçam as identidades dos

\footnotetext{
${ }^{3}$ Alemanha, Canadá, Estados Unidos, França, Itália, Reino Unido.

${ }^{4}$ A Rússia foi excluída em 2014 devido à anexação da Criméia.
}

Revista Brasileira de Políticas Públicas e Internacionais, v.4, n.1, julho/2019, pp. 175-194. 
XAVIER, Marcelo; FONSECA, Pedro. IBAS: uma análise das ações quinze anos depois.

países é o fato de possuírem uma liderança regional, parques industriais desenvolvidos e mercados emergentes; aspirações a uma vaga permanente ao Conselho de Segurança da ONU; constarem como potências médias e, por fim, compartilharem problemas socioeconômicos, como desigualdade social e de renda.

Uma das premissas que orientam a ação do IBAS é o respeito às instituições multilaterais de governança global. Contudo, asseveram que as mudanças ocorridas desde a fundação das Nações Unidas e, em particular, o Conselho de Segurança não refletem a correlação de forças atuais. Por isso reiteram ao longo de todos os encontros que a inclusão de países em desenvolvimento é um ato de justiça e de reconhecimento do relevo de novos atores internacionais.

A pauta de reforma do sistema internacional de governança em todas suas instâncias é tema central do Fórum IBAS. Desde o primeiro encontro do grupo há o reforço explícito dessa ideia e uma manifestação conjunta sobre os temas que envolvem a comunidade internacional, numa tentativa de mostrar a posição do grupo e capacidade de propor soluções. Há uma clara associação entre a continuidade do bem-estar dos países em desenvolvimento e mudança na estrutura de poder global, ora representada pela abertura de novos assentos permanentes no Conselho de Segurança da ONU.

A criação do Fundo IBAS concorre no sentido de aprofundar a presença dos três membros como articuladores de ações de combate à fome e miséria no mundo, a exemplo de instituições tradicionais como o Banco Mundial. Também é uma demonstração da capacidade de articulação de países do Sul para resolver seus próprios problemas e ainda servir de exemplo de boa governança. Além disso, emerge como uma ferramenta para obter prestígio e liderança perante os países contemplados com os projetos e assim estabelecer uma rede paralela de governança em temas que compõe os Objetivos do Milênio.

São diversas as manifestações do IBAS sobre questões diversas ao da agenda global. Sempre se posicionando em favor do pacifismo, as Declarações dos sucessivos Fóruns e os encontros ministeriais marcaram posição a respeito da situação de países como a Síria, Afeganistão, Sudão, Palestina, Iran, Iraque, Guiné-Bissau e Haiti. Além disso, há uma constante tentativa de manter alinhamento com acordos regionais de cooperação (Mercosul, Nova Parceria para o Desenvolvimento da África e UNASUL).

Revista Brasileira de Políticas Públicas e Internacionais, v.4, n.1, julho/2019, pp. 175-194. 
XAVIER, Marcelo; FONSECA, Pedro. IBAS: uma análise das ações quinze anos depois.

Sobressai também a importância dada ao combate à AIDS/HIV, que é colocada com uma ameaça à segurança internacional, no mesmo patamar de terrorismo, tráfico de drogas, armas e desastres naturais. Essa é uma preocupação dos países-membros do IBAS, que também acomete a maioria dos países periféricos, mostra o interesse de tornar a agenda do Sul parte da agenda global de problemas a serem enfrentados.

A convergência da atuação também se expressa no âmbito de outros arranjos multilaterais em pontos comuns, a exemplo dos preparativos para a Rodada de Cancún em 2003 quando o IBAS nos seus primeiros passos liderou as discussões dentro do G20 sobre as disputas para liberalização do comércio internacional de gêneros agrícolas de interesse dos membros do grupo contra o protecionismo dos países desenvolvidos (Husar, 2017).

A atuação do IBAS pode ser dividida em três vertentes. A primeira diz respeito sobre coordenação política, em que os membros do IBAS buscam posições conjuntas em temas como democracia, direitos humanos, inclusão social e desenvolvimento sustentável. A segunda versa sobre cooperação setorial, onde por meio de três pilares do desenvolvimento sustentável, sendo eles o desenvolvimento social, econômico e ambiental, buscam "maior eficiência e efetividade das iniciativas de cooperação trilateral" e a terceira é o Fundo IBAS, voltado para promover a cooperação com outros países (Itamaraty, 2017).

\subsection{O Fundo IBAS}

O Fundo IBAS é desenhado com o objetivo de promover projetos em "países de menor desenvolvimento relativo ou egressos de conflitos" (IBAS, 2003). Cabe destacar que esse é lado mais visível do IBAS no que tange a realização conjunta de projetos. Criado em 2004 após a I Reunião de Comissão Mista, o Fundo IBAS para o Alívio da Pobreza e da Fome iniciou suas operações em 2006 e é apoiado e dirigido pelos governos dos países-membros, além de ser gerenciado pela Unidade Especial para Cooperação Sul-Sul (SU-SSC) ${ }^{5}$ organizada pelo Programa das Nações Unidas para o Desenvolvimento (PNUD).

O Fundo IBAS não põem condicionantes para os países que necessitam do apoio, no entanto, os princípios fundamentais do Fundo são que os projetos de cooperação devem ser orientados pela necessidade, bem como ser de propriedade local e gerenciados para assegurar a

\footnotetext{
${ }^{5}$ Special Unit for South-South Cooperation (SU-SSC)
}

Revista Brasileira de Políticas Públicas e Internacionais, v.4, n.1, julho/2019, pp. 175-194. 
XAVIER, Marcelo; FONSECA, Pedro. IBAS: uma análise das ações quinze anos depois.

sustentabilidade e a continuidade dos resultados de desenvolvimento no terreno (IBSA, 2017). Desse modo, o IBAS ressalta a importância do impacto de capacitação em seus projetos; favorece a aquisição local; e promove o uso da expertise do sul (IBSA, 2017).

Os governos que possuem interesse no apoio enviam suas propostas ao Fundo. Tais propostas são avaliadas de acordo com os seguintes critérios: i) Redução da pobreza e da fome; ii) Propriedade nacional e liderança; iii) Cooperação Sul-Sul; iv) Uso das capacidades do país IBAS; v) Fortalecimento da capacidade local; vii) Propriedade; Sustentabilidade; Impacto identificável; viii) Replicabilidade; ix) Inovação; x) Prazo e Tamanho do projeto (IBSA, 2017). A partir disso, as propostas que recebem uma indicação favorável do IBAS são apresentadas para o Conselho de Administração do Fundo IBAS, composto pelos Representantes Permanentes Adjuntos do IBAS nas Nações Unidas em Nova York.

O Conselho de Administração do IBAS se reúne trimestralmente para rever e aprovar novos projetos, bem como monitorar a execução de projetos e fornecer orientação estratégica para atividades em andamento (IBSA, 2017). Já a Unidade Especial para Cooperação Sul-Sul atua como o gerente do fundo e a Secretaria do Conselho de Administração e inicia contato com potenciais agências de execução para avançar a formulação de projetos do IBAS para facilitar e apoiar a implementação (IBSA, 2017).

Para gerir todos os projetos aprovados, o Fundo IBAS conta com US\$ 35 milhões em contribuições acumuladas em 2017 (Figura 1), além de uma cota anual por parte dos paísesmembros de US\$ 1 milhão e 19 Estados parceiros, sendo a maioria países em desenvolvimento (IBSA Fund, 2018).

É necessário notar a evolução das contribuições financeiras ao Fundo durante o período de 2004 a 2017. O acumulado de contribuição cresceu cerca de 6 vezes entre o período de 2006 a 2017. Tal fato mostra que potencial de ajuda do Fundo vem evoluindo ao longo do tempo, colocando o IBAS como um importante organismo de cooperação sul-sul.

Revista Brasileira de Políticas Públicas e Internacionais, v.4, n.1, julho/2019, pp. 175-194. 
XAVIER, Marcelo; FONSECA, Pedro. IBAS: uma análise das ações quinze anos depois.

Figura 1: Contribuições financeiras para o Fundo IBAS em US\$ (2004-2017)

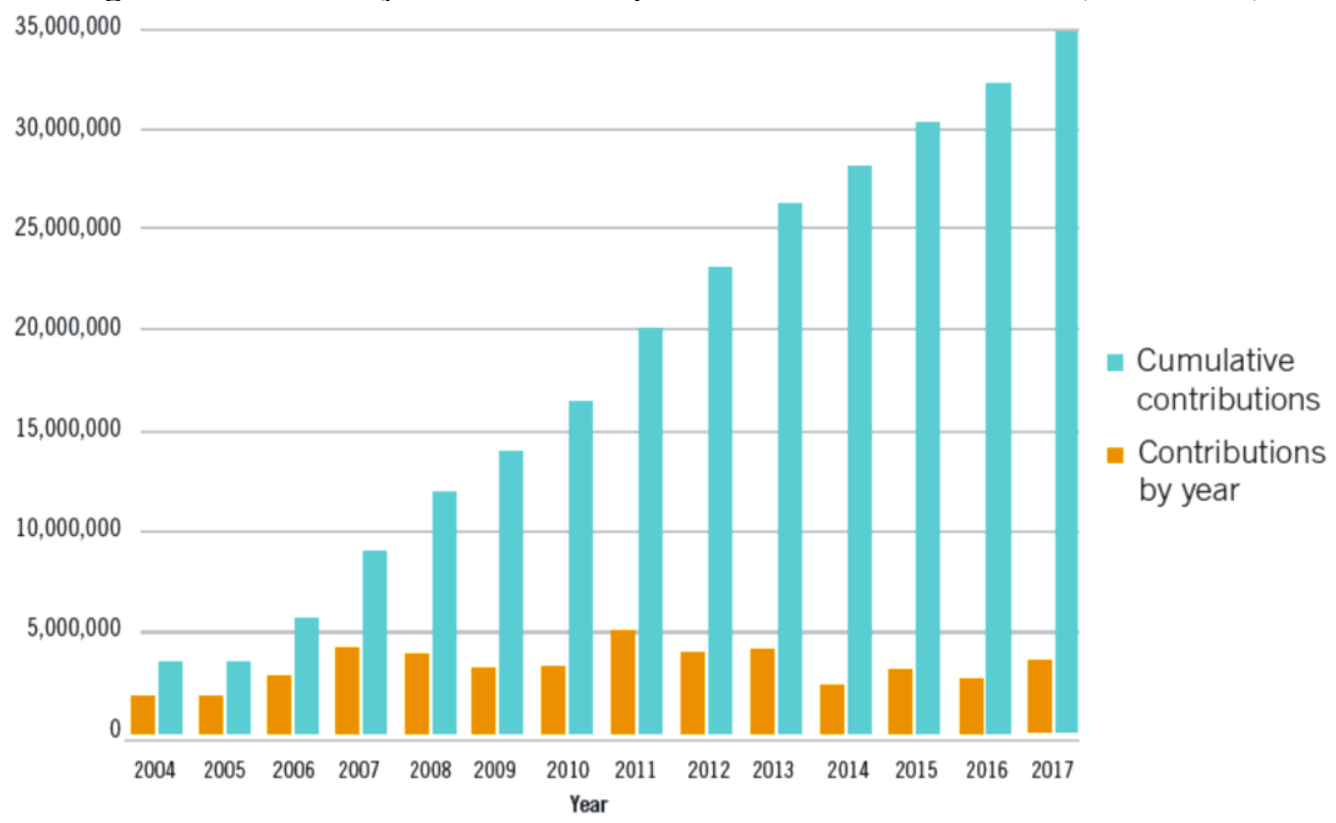

Fonte: IBSA Fund (2018)

Outro fator a ser notado são as aplicações financeiras aos projetos desenvolvidos pelo fundo. Observa-se na Figura 2 que até 2009 o acumulado não ultrapassava US\$ 4 milhões, no entanto já em 2010, nota-se um crescimento que ultrapassa, em 2017, a marca de US\$ 25 milhões.

Figura 2: Execução financeira dos projetos em US\$ (2004-2017)

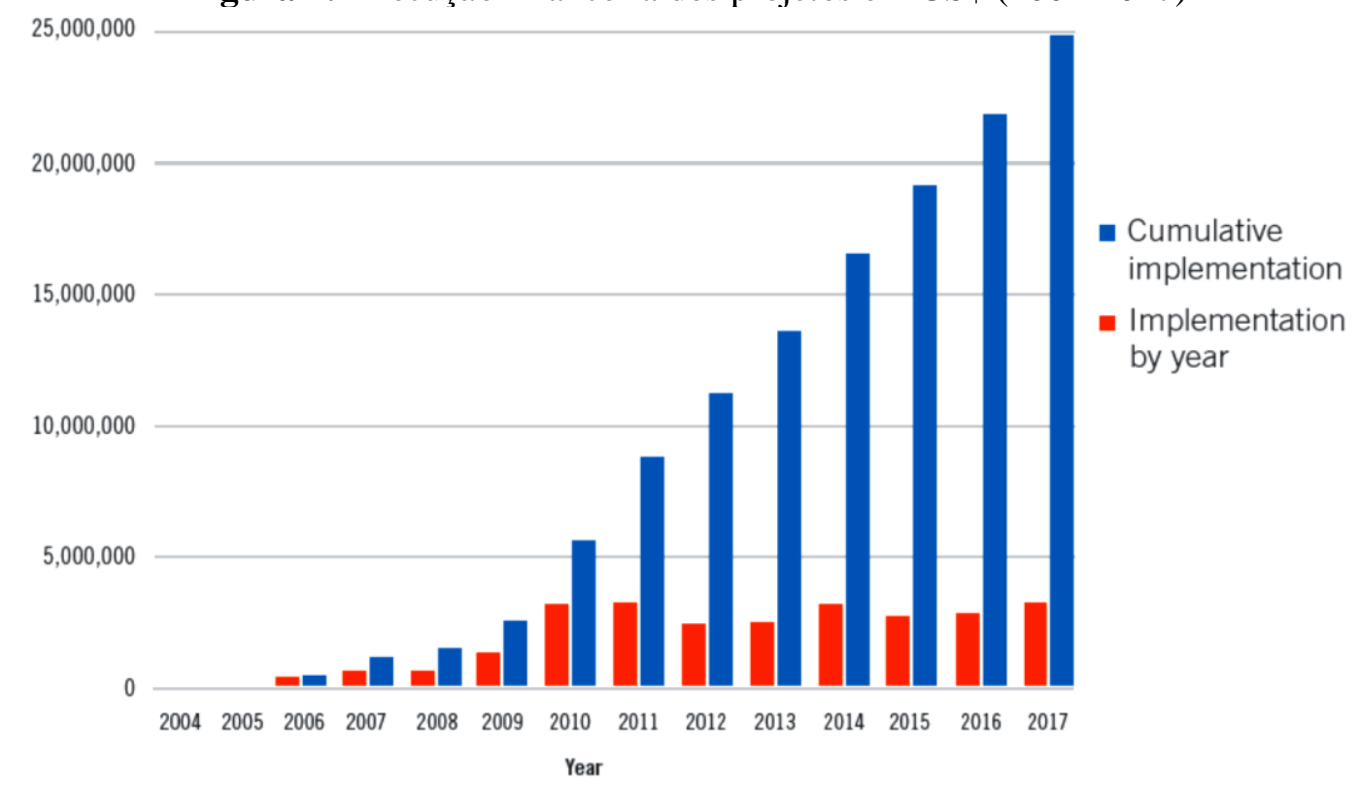

Fonte: IBSA Fund (2018)

Revista Brasileira de Políticas Públicas e Internacionais, v.4, n.1, julho/2019, pp. 175-194. 
XAVIER, Marcelo; FONSECA, Pedro. IBAS: uma análise das ações quinze anos depois.

Dados do Overview of the IBSA Fund Project Portfolio 2018 apresentam um total de 29 projetos do financiados Fundo IBAS. Esses projetos são divididos em três categorias, projetos em progresso, aprovados e completos. A partir disso, 9 projetos são classificados como estando “em progresso", enquanto 5 na categoria “aprovados” e 15 na categoria de "concluídos".

Entretanto, observou-se que entre os 9 projetos classificados como "em andamento", 3 foram finalizados de acordo com a data prevista apresentada no relatório. São eles: Projeto de "Melhoria da gestão de resíduos sólidos", na Guiana, de abril de 2014 a setembro de 2018; "Promoção a integração socioeconômica de crianças e jovens vulneráveis", no Haiti, entre julho de 2015 e dezembro de 2017, e o Projeto de "Redução da pobreza através do desenvolvimento da pecuária”, em Santa Lúcia, entre junho de 2015 e setembro de 2018.

Ao analisar os projetos aprovados, também foi observado que todos já estão em fase de execução de acordo com as datas apresentadas no relatório. Dessa maneira, optou-se por incluir a categoria de projetos "aprovados" em "em progresso" e de transferir os 3 projetos concluídos que estavam na categoria "em andamento" para "concluídos".

Tabela 1: Projetos financiados pelo Fundo IBAS.

\begin{tabular}{ccc}
\hline Projetos & Quantidade & Montante (US\$ mil.) \\
\hline Em progresso & 14 & 14.697 .925 \\
\hline Concluídos & 15 & 18.095 .137 \\
\hline Total & 29 & 33.063 .062 \\
\hline
\end{tabular}

Fonte: Elaboração própria com base nos dados de IBSA Fund (2018)

No que diz respeito aos investimentos, os dados coletados apresentam que o fundo IBAS financia/financiou 29 projetos, sendo 14 projetos considerados em progresso e 15 concluídos. O montante investido foi de cerca de US\$ 33 milhões dos quais US\$ 14.697.925 foram para projetos que estão progresso, enquanto US\$18.095.137 foram destinados para projetos concluídos (Tabele 1). Outro ponto importante a ser observado são os setores a que se destina a ajuda financeira do Fundo. Em 2017, a área que mais recebeu aprovação de recursos foi a agricultura com quase 34\%. Em seguida temos cuidados com a Emprego e Meio de Subsistência com 21,2\% e Saúde com 20,9\% (Figura 3).

Revista Brasileira de Políticas Públicas e Internacionais, v.4, n.1, julho/2019, pp. 175-194. 
XAVIER, Marcelo; FONSECA, Pedro. IBAS: uma análise das ações quinze anos depois.

Figura 3: Aprovações orçamentais: Área temática em 2017.

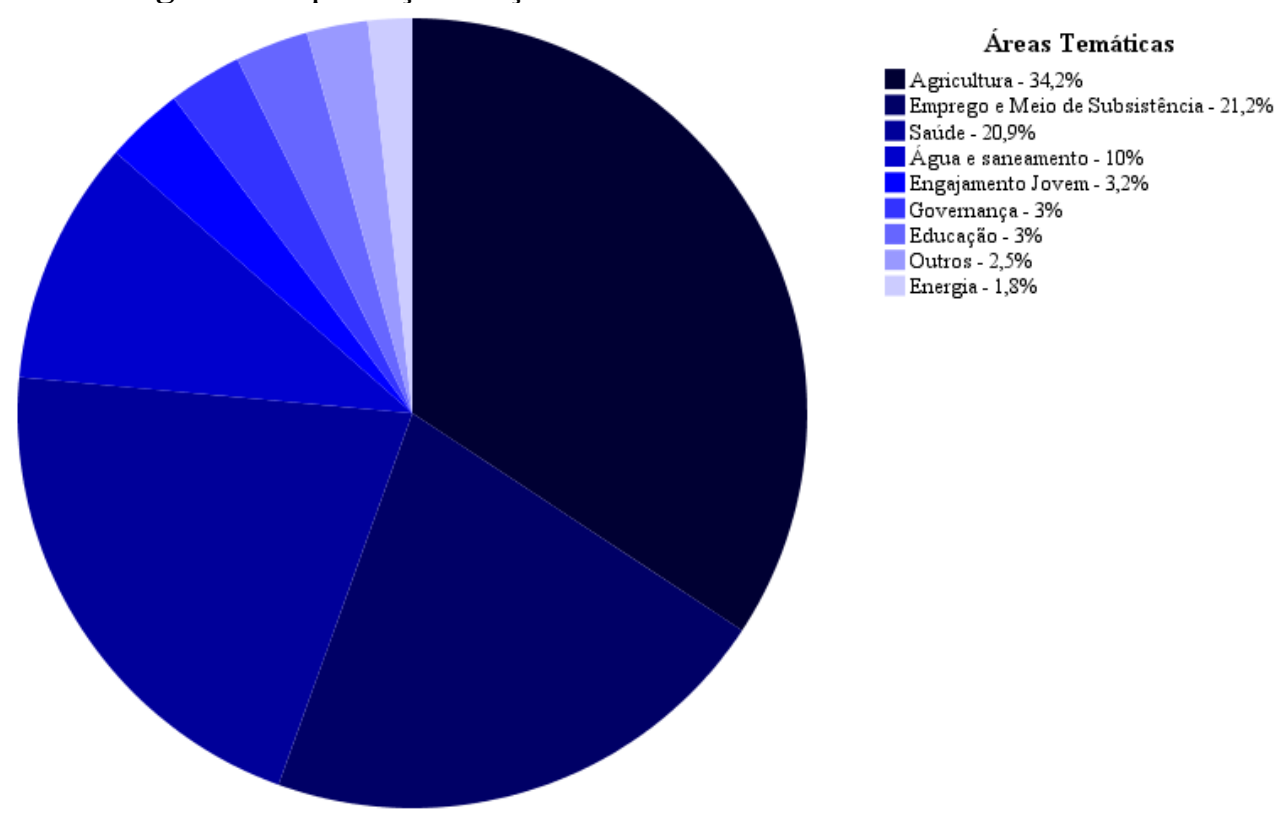

Fonte: Elaboração própria com base no dado de IBSA Fund (2018)

As regiões que mais receberam ajuda do Fundo IBAS no ano de 2017 foram a África, principal região receptora, sendo destinado para o continente $37 \%$ do orçamento, América Latina (24,5\%), Ásia e Estados Árabes com 20,9\% e 15,1\%, respectivamente (Figura 4). Além disso cerca de $64 \%$ dos projetos aprovados foram em países considerados menos desenvolvidos (IBSA Fund, 2018). Isso corrobora com o argumento de que o IBAS é um importante agente na cooperação Sul-Sul e que desenvolve esforços para promover o desenvolvimento e atenuar o subdesenvolvimento.

Revista Brasileira de Políticas Públicas e Internacionais, v.4, n.1, julho/2019, pp. 175-194. 
XAVIER, Marcelo; FONSECA, Pedro. IBAS: uma análise das ações quinze anos depois.

Figura 4: Aprovações orçamentais: Localidade geográfica.

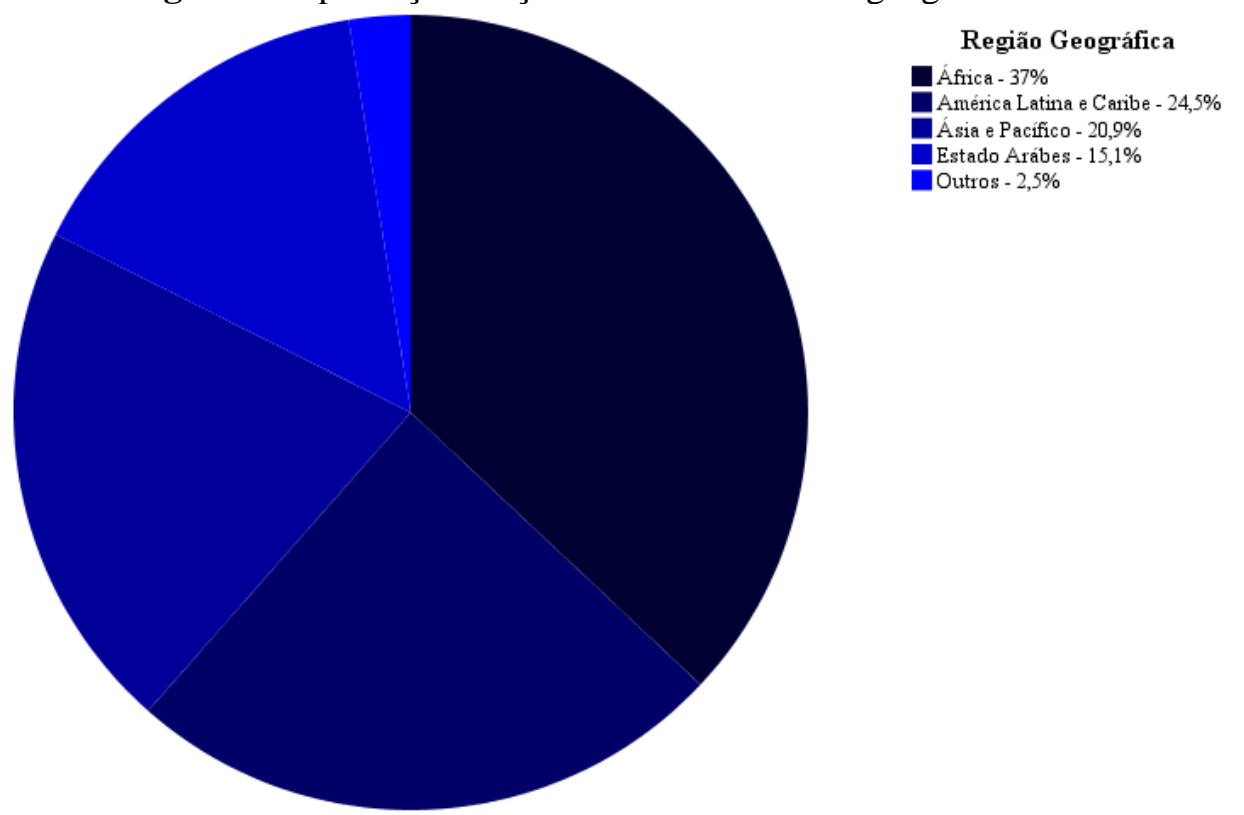

Fonte: Elaboração própria com base nos dados de IBSA Fund (2018)

Com cerca de 17 metas de desenvolvimento sustentável avançadas nas áreas de erradicação da pobreza e da fome, educação, igualdade de gênero, saúde infantil e materna, prevenção e cuidados de HIV/AIDS, sustentabilidade ambiental e parcerias globais (IBSA Fund, 2018), o IBAS, através do seu fundo, desenvolve inúmeros projetos nos países em desenvolvimento. Projetos como o que ocorreu em Burundi de fortalecimento da infraestrutura e capacidade de combater o AIDS no período que corresponde janeiro de 2010 a dezembro de 2012. Em parceria com o Ministério da Saúde de Burundi, Society for Women Against AIDS (SWAA), Programa das Nações Unidas para o Desenvolvimento (UNDP) e o Fundo de População das Nações Unidas (UNFPA); o Fundo IBAS construiu e equipou um centro de prevenção, teste e tratamento de AIDS, fornecendo também outros serviços de saúde, cobrindo saúde reprodutiva, doenças sexualmente transmissíveis, pré-natal e planejamento familiar (IBSA Fund, 2018).

Outro importante projeto que está em curso recentemente aprovado foi o da redução da pobreza entre jovens no Camboja que tem como objetivo desenvolver um conjunto de habilidades de voluntários juvenis para maior empregabilidade. Em parceria com o Ministério

Revista Brasileira de Políticas Públicas e Internacionais, v.4, n.1, julho/2019, pp. 175-194. 
XAVIER, Marcelo; FONSECA, Pedro. IBAS: uma análise das ações quinze anos depois.

da Educação, Juventude e Esporte do Camboja e uma rede de voluntários, o projeto busca impactar cerca de mil jovens.

É válido lembrar que desde sua criação até 2018, o Fundo IBAS aprovou 32 projetos para 21 países com o foco em áreas críticas para o alcance dos Objetivos do Desenvolvimento Sustentável. Mais recentemente foram aprovados os projetos para acabar com o casamento infantil de meninas no Malawi e Zâmbia (UNOCSS, 2018). Outro projeto fornece acesso a serviços financeiros a 100.00 pequenos agricultores em Serra Leoa (UNOCSS, 2018). O sucesso do Fundo levou à assinatura pelos ministros dos três países de um acordo para garantir o fluxo de aporte de recursos para o fundo, assegurando a continuidade dos projetos (UNOCSS, 2017). Os esforços realizados para combater os problemas que afetam os países do sul global através do fortalecimento da cooperação Sul-Sul, além de aperfeiçoar a cooperação trilateral, o Fundo IBAS ganhou reconhecimento da comunidade internacional.

Os êxitos do Fundo foram reconhecidos anteriormente em 2006 quando o IBAS foi homenageado com o Prêmio "Parceria Sul-Sul para Aliança Sul-Sul "concedido pelo Programa das Nações Unidas para o Desenvolvimento (PNUD) e o prêmio "Millennium Development Goals Awards" da ONG Millennium Development Goals Awards Committee em 2010, por utilizar abordagens inovadoras para compartilhar, reproduzir e atualizar experiências de desenvolvimento bem-sucedidas para erradicar a pobreza e a fome no mundo. Por fim, em 2012, o Escritório das Nações Unidas para a Cooperação Sul-Sul entrega o "South-South and Triangular Cooperation Champions Award", pela contribuição inovadora para a cooperação Sul-Sul e para a cooperação triangular.

\subsection{Cooperação Setorial}

Outro desafio para os membros do IBAS é fomentar a coordenação setorial e promover a aproximação entre países que historicamente não são aliados de primeira ordem. Parte-se do reconhecimento de que os três países apresentam carências e potencialidade em diversas áreas técnicas. Através do compartilhamento de experiências e trabalho conjunto busca-se sanar as deficiências e impulsionar conjuntamente as competências dos países-membros. Assim foram

Revista Brasileira de Políticas Públicas e Internacionais, v.4, n.1, julho/2019, pp. 175-194. 
XAVIER, Marcelo; FONSECA, Pedro. IBAS: uma análise das ações quinze anos depois.

criados dezesseis ${ }^{6}$ fóruns setoriais e fóruns não governamentais para aproximar, buscar a identificação de complementaridades e compartilhar de experiências em áreas diversas.

Não será traçada uma análise pormenorizada e cada grupo de trabalho, pois foge ao escopo do trabalho. Ainda assim alguns grupos se destacaram mais do que os demais e por isso merece comentários.

Na opinião de Stuenkel (2015) e Faria, Nogueira e Lopes (2012), a baixa produtividade dos grupos de trabalho pode ser atribuída à distância geográfica entre os países, a barreira da língua e o calendário de encontros, que não são coincidentes. Apontam também que alguns grupos de trabalho se dedicaram a questões que não figuravam entre as prioridades políticas nas agendas do Fórum IBAS. Como os grupos são patrocinados pelos recursos orçamentários dos ministérios relacionados como o tema, uma vez não sendo provido pelos governos internamente os grupos não terão condições de avançar. Além disso, o próprio número de grupos de trabalho dificulta a coordenação, a definição da pauta individual e como se integração numa proposta mais geral.

Além disso há problemas de conflitos de interesses entre os membros como no caso do grupo de trabalho da Agricultura. Criado em 2005, nasceu com uma clara divergência entre Brasil e Índia de longa data. O Brasil defende a liberalização do comércio e a Índia mantém uma postura defensiva para salvaguardar os produtores internos, que são pouco competitivos, mas cumprem uma função importante dentro da economia indiana. Apesar dos os esforços brasileiros para construir uma agenda mínima que permitisse algum avanço nenhuma ação efetiva foi concretizada, de modo que o grupo até o momento não encontrou demandas em comum entre os países-membros (Stuenkel, 2015).

Em sentido contrário, o projeto IBSAMAR exibe a convergência entre os paísesmembros. Criado em 2004 com a finalidade de integrar as forças marítimas nacionais através de exercícios militares periódicos. Entre 2008 e 2018 foram realizados seis exercícios conjuntos pelas Marinhas nacionais a cada dois anos. A regularidade de tais exercícios sugere que as ações do grupo de trabalho seguem com êxito.

\footnotetext{
${ }^{6}$ Agricultura, cultura, defesa, educação, energia, saúde, moradia, Administração Pública, Receitas públicas, ciência e tecnologia, informação, comércio e investimento, turismo, transporte e desenvolvimento social.
}

Revista Brasileira de Políticas Públicas e Internacionais, v.4, n.1, julho/2019, pp. 175-194. 
XAVIER, Marcelo; FONSECA, Pedro. IBAS: uma análise das ações quinze anos depois.

Merece uma nota em destaque o grupo setorial voltado para tratar do comércio e investimento, afinal é uma pauta transversal a outros grupos de trabalho. Este surgiu em 2004 com o objetivo de desenhar acordos comerciais internos ao grupo e atrair o investimento externo. No limite, o objetivo é promover um acordo de livre comércio na perspectiva do regionalismo moderno ${ }^{7}$. Contudo, tal meta envolve necessariamente incorporar os países do Mercosul e do $\mathrm{SACU}^{8}$, uma vez que Brasil e África do Sul integram uniões aduaneiras anteriores, o que torna a tarefa ainda mais complexa (Husar, 2017).

Os encontros do grupo de trabalho evoluíram ao longo dos anos de 2007 e 2008 até que em 2009. Neste ano, os ministros de comércio exterior dos países do Mercosul, SACU e Índia deliberaram para que fossem elaborados estudos sobre a possibilidade de um acordo de livre comércio entre os três entes, muito embora ainda não exista nada de concreto.

Como não há acordo algum intra IBAS, é bem provável que o desempenho das relações comerciais seja causado por outros fatores. Ainda assim, Schor (2014) defende que a o comércio é um item de relevo para o IBAS exatamente por que é pouco explorado e arranjos podem ser construídos.

A concentração da pauta é uma evidencia de que as relações comerciais ainda são muito restritas. Em 2017, cinco principais produtos de exportação do Brasil para a Índia corresponderam a $70 \%$ do total das exportações para aquele país. No caso da África do Sul, os cinco principais produtos somavam $40 \%$ das exportações. Pelo lado das importações brasileiras, o percentual é o mesmo para os cinco produtos que mais Brasil compra. As importações brasileiras da Índia foram bem mais diversificadas em 2017, e somaram 15\% apenas.

O crescimento do volume de comércio foi significativo ao longo dos anos 2000. A tendência era evidente desde o início da década, mas deu um salto por volta de 2005 e novamente depois de 2009, talvez motivado pelo surgimento efetivo dos BRICS e o efeito da economia chinesa, que ainda crescia a taxas elevadas.

\footnotetext{
${ }^{7}$ Segundo Oliveira (2013), o regionalismo consiste em ações no sentido de diminuir ou retirar por completo barreiras ao comércio a partir de acordos dos mais diversos tipos.

${ }^{8}$ União Aduaneira da África do Sul formada por África do Sul, Botswana, Lesoto, Suazilândia e Namíbia.
}

Revista Brasileira de Políticas Públicas e Internacionais, v.4, n.1, julho/2019, pp. 175-194. 
XAVIER, Marcelo; FONSECA, Pedro. IBAS: uma análise das ações quinze anos depois.

\section{Considerações Finais}

O presente trabalho buscou examinar os resultados do Fórum IBAS após quinze anos de sua fundação, analisando as principais ações e observando, principalmente o Fundo IBAS, entendido como o principal instrumento utilizado para a execução dos projetos propostos.

A criação do Fundo IBAS aparece como um instrumento de demonstração das capacidades do fórum em articular projetos ao redor do mundo e empregar recursos em consonância com os Objetivos do Milênio. Ao mesmo tempo, dá relevo ao combate à pobreza e deixa claro que os avanços nesse sentido dependem inclusive de modificações na governança global, que deve refletir as mudanças na correlação de forças entre os Estados. O fundo IBAS contribui para a consolidar a imagem dos patrocinadores e talvez torná-los mais atrativos para futuras parcerias.

No que se refere a cooperação político-setorial o IBAS apresenta um corpo com 16 grupos de trabalho que servem de mecanismo para promover a cooperação e o intercâmbio de conhecimento entre os países em diferentes áreas (Silva \& Adriotti, 2012). Embora os avanços sejam marginais e assimétricos, o Fórum de Diálogo IBAS cumpre sua de aproximar e os países e dar sentido à cooperação Sul-Sul, promovendo "um amplo leque de temas, que vão do comércio até a questão de segurança internacional” (Vigevani \& Cepaluni, 2007, p. 296).

Dessa maneira, ao analisar os resultados que o Fórum de Diálogos IBAS nota-se um esforço dessa cooperação bem arquitetada e rica em demandas importantes para os países do Sul global para resolver questões pertinentes para o desenvolvimento. O avanço demandará que os países-membros superem problemas internos e talvez conflitantes com os princípios propostos pelo Fórum. Para além disso, num contexto mundial que vem sendo desenhado e imaginado no século XXI, o IBAS possuí potencial de se tornar uma importante ferramenta de diálogo e desenvolvimento entre os membros e demais países do Sul global.

Mesmo diante de tamanhos desafios, a experiência do IBAS mostra aos países do sul global as possibilidades dos ganhos da atuação conjunta. Desse modo, aliando-se em torno de interesses comuns, esses países maximizam a chance de sucesso, além de aprofundar os lanços de confiança, garantindo aliados na defesa de futuras questões significativas.

Revista Brasileira de Políticas Públicas e Internacionais, v.4, n.1, julho/2019, pp. 175-194. 
XAVIER, Marcelo; FONSECA, Pedro. IBAS: uma análise das ações quinze anos depois.

E é nesse aprofundamento das relações que as organizações como IBAS ou BRICS desempenham um papel importante, visto que é necessário que os países adotem o multilateralismo dentro das organizações. Ou seja, as pautas comuns das nações as impelem a cooperar e construir uma rede de confiança. Dentro do campo das relações internacionais há o debate se o multilateralismo é o mais adequado para a balança de poder, no entanto, mostrou-se como uma importante ferramenta dos países do sul global na política internacional.

Essa nova configuração de poder não ocorre sem resistência. $\mathrm{O}$ desenvolvimento de novos organismos de CSS vem acompanhado da oposição dos Estados Unidos. Além disso, observa-se ascensão chinesa, principal ator em disputa com os EUA pela a hegemonia é a China, uma potência emergente que vem desafiando, e em certas áreas superando, a hegemonia norte-americana.

De todo modo, o século XXI se apresenta como sendo de ascensão de novos atores, ou seja, atores emergentes e não-ocidentais Stuenkel (2018). A partir dessa configuração, é importante notar que os países que não busquem participar de organismos multilaterais com potências médias e não ocidentais, tendem a se isolar nas pautas da política internacional ou não ter sucesso na defesa de seus interesses. Para algumas nações, se esse impacto será em maior ou menor grau, dependerá do seus status na política global e no seu poder efetivo, ou seja, econômico, político ou militar.

\section{Referências}

ABC - Agência Brasileira de Cooperação (2012). Conceito de Cooperação. Recuperado em 06/12/2017, de http://www.abc.gov.br/CooperacaoTecnica/Conceito.

Almeida Filho, J. G. de (2009). O fórum de diálogo Índia, Brasil e África do Sul (IBAS): análise e perspectivas / João Genésio de Almeida Filho. Brasília: Fundação Alexandre de Gusmão.

Amorim, C. (2013). Breves narrativas diplomáticas. São Paulo: Benvirá.

Brasil - Itamaraty (2019). IBAS - Fórum de Diálogo Índia, Brasil e África do Sul. Itamaraty. Recuperado em 10/12/2017, de http://www.itamaraty.gov.br/pt-BR/politicaexterna/mecanismos-interregionais/3673-forum-de-dialogo-india-brasil-e-africa-do-sul-ibas.

Revista Brasileira de Políticas Públicas e Internacionais, v.4, n.1, julho/2019, pp. 175-194. 
XAVIER, Marcelo; FONSECA, Pedro. IBAS: uma análise das ações quinze anos depois.

De La Fontaine, D. \& Seifert, J. (2010). The Role of South-South Cooperation in present Brazilian Foreign Policy: Actors, Interestsand Functions. Institute of Latin American Studies.

Faria, C., Nogueira, J., \& Lopes, D. (2012). Coordenação Intragovernamental para a Implementação da Política Externa Brasileira: O Caso do Fórum IBAS. DADOS - Revista de Ciências Sociais, Rio de Janeiro, 55 (1), 173-220. Recuperado em 04/01/2018, de http://www.scielo.br/pdf/dados/v55n1/a05v55n1.pdf.

Husar, J. (2016). Fraiming Foreign in India, Brazil and South Africa. Paris: Springer.

IBAS - Fórum de Diálogo Índia-Brasil-África do Sul (2003). Declaração de Brasília. Recuperado em 15/12/2017, de http://www.cnpq.br/documents/10157/7745fcb0-5759-4edcb8b2-8a1e81c2a9fc.

IBSA (2017). About IBSA. Recurado em 10/12/2017, de http://www.ibsa-trilateral.org/aboutibsa/ibsa-fund.

IBSA Fund (2018). Overview of the IBSA Fund Project Portfolio. Organizador: Ines Tofalo. Recuperado em 15/02/2019, de http://tcdc2.undp.org/IBSA/Upload/UNDP\%20IBSA\%20Report\%202017\%200nline\%20Final 2.pdf.

Milani, C. R. S. \& Carvalho, T. C. O. (2013, janeiro/junho). Cooperação Sul-Sul e Política Externa: Brasil e China no continente africano. Estudos Internacionais. 1 (1), 11-35, 2013.

Narlikar, A. (2010). New Powers: HowtoBecomeOneandHowtoManageThem. New York: Columbia.

Oliveira, I. T. (2013). A Política Comercial Externa Brasileira: uma análise de seus determinantes. São Paulo: Editora Saraiva.

UNOCSS - United Nations Office for South-South Cooperation (2017). Índia, Brazil and South Africa sign agrément for continued contributions to the IBSA Fund. Recuperado em 16/12/2018, de https://www.unsouthsouth.org/2017/10/18/india-brazil-and-south-africa-signagreement-for-continued-contributions-to-the-ibsa-fund/.

(2018). IBSA board approves digital finance Project in Sierra Leone. Recuperado em 16/12/2018, de https://www.unsouthsouth.org/2018/03/10/ibsa-board-approves-digitalfinance-project-in-sierra-leone/.

(2018). IBSA Fund approves Project on ending child marriage in Malawi and Zambia. Recuperado em 16/12/2018, de https://www.unsouthsouth.org/2018/08/09/ibsa-fundapproves-project-on-ending-child-marriage-in-malawi-and-zambia/.

Revista Brasileira de Políticas Públicas e Internacionais, v.4, n.1, julho/2019, pp. 175-194. 
XAVIER, Marcelo; FONSECA, Pedro. IBAS: uma análise das ações quinze anos depois.

Renzio, P., Gomes, G., Fonseca, J., \& Niv, A. (2013). O Brasil e a Cooperação Sul-Sul: Como Responder aos Desafios Correntes. Rio de Janeiro: BRICS POLICY CENTER/Centro de Estudos e Pesquisas - BRICS.

Silva, A. L. R. \& Adriotti, L. S. (2012). A Cooperação Sul-Sul na Política Externa do Governo Lula (2003-2010). Revista Conjuntura Austral, 3 (14).

Schor, A. (2014). South-South Cooperation and IBSA: More Trade in Politics. New Global Studies, 8(2), 183-201.

Stuenkel, O. (2015). India-Brazil-South Africa Dialogue Forum (IBSA). Nova York: Routledge.

$1^{\mathrm{a}}$. Editora Zahar.

(2018). O mundo pós-ocidental: Potências emergentes e a nova ordem global. Ed.

Vigevani, T. \& Cepaluni, G. (2007). A política externa de Lula da Silva: a estratégia da autonomia pela diversificação. Contexto internacional, 29 (2), 273-335.

Revista Brasileira de Políticas Públicas e Internacionais, v.4, n.1, julho/2019, pp. 175-194. 